\title{
SOLUBILIZAÇÃO DE FOSFATO INORGÂNICO POR FUNGOS RIZOSFÉRICOS ASSOCIADOS À CACTÁCEAS DO SEMIÁRIDO ALAGOANO
}

\author{
João Manoel da Silva ${ }^{1}$, Crísea Cristina Nascimento de Cristo², Yamina Coentro Montaldo ${ }^{3}$, Tania Marta Carvalho \\ dos Santos ${ }^{3}$, Gaus Silvestre de Andrade Lima ${ }^{3}$
}

\begin{abstract}
${ }^{1}$ Rede Nordeste de Biotecnologia, Instituto de Química e Biotecnologia - IQB, Universidade Federal de Alagoas ${ }^{2}$ Instituto Federal de Educação, Ciência e Tecnologia de Alagoas, Campus Murici

${ }^{3}$ Centro de Ciências Agrárias, Universidade Federal de Alagoas
\end{abstract}

\begin{abstract}
RESUMO: Objetivou-se por meio desse estudo avaliar a solubilização de fosfatos inorgânicos por fungos rizosféricos associados à cactáceas. Para tanto, foram utilizadas seis cepas fúngicas (F01, F02, F03, F04, F05, F06), as quais estão depositadas na coleção de micro-organismos do Laboratório de Microbiologia do Centro de Ciências Agrárias (UFAL), os quais foram submetidos à inoculação em erlenmeyers de $125 \mathrm{~mL}$ contendo $100 \mathrm{~mL}$ de meio de cultivo NBRIP, e incubados sob agitação orbital contínua (120 rpm) durante 15 dias, sendo coletado $1 \mathrm{~mL}$ de cada amostra a cada 5 dias. Em seguida, foi realizada centrifugação e de cada amostra retirado $145 \mu \mathrm{L}$ e acondicionado em microtubo de $2 \mathrm{~mL}$. Em seguida foi adicionado $570 \mu \mathrm{L}$ de água destilada e $285 \mu \mathrm{L}$ do reagente Molibidato-Vanadato de Amônio. Dez minutos após a adição do reagente, foi realizada a leitura da absorbância em espectrofotômeto (modelo UV - SP 2000 Biospectro) sob densidade ótica de $420 \mathrm{~nm}$ e aplicados na fórmula $\left(y=0,3041^{*} X^{2}+0,2566^{*} X+0,0213\right) * 1000$. 0 delineamento experimental foi inteiramente casualizado com quatro repetições em esquema de parcela subdividida no tempo. Os dados obtidos foram submetidos à análise de variância e as médias comparadas pelo teste de Tukey $(p>0,05)$. Os resultados mostraram uma faixa de 10-141 $\mu \mathrm{g} \cdot \mathrm{mL}^{-1} \mathrm{P}$, caracterizando com alta solubilização e conferindo essas cepas como solubilizadoras de fosfato. As cepas mais eficientes foram F04 e F05.
\end{abstract}

PALAVRAS-CHAVE: Fungos filamentosos, fosfatase, fosfato de cálcio

\section{INORGANIC PHOSPHATE SOLUBILIZATION BY RIZOSPHERIC FUNGI CACTI-ASSOCIATED FROM ALAGOAN SEMIARID}

\begin{abstract}
The aim of this study was to evaluate the inorganic phosphate solubilization by cacti-associated rizospheric fungi. Thus, was used six fungal strains (F01, F02, F03, F04, F05, F06), which are deposited in the collection of microorganisms of the Microbiology Laboratory of the Center for Agrarian Sciences (UFAL), which were submitted to inoculation in erlenmeyers of $125 \mathrm{~mL}$ containing $100 \mathrm{~mL}$ of NBRIP culture medium, and incubated under orbital mix (120 rpm) for 15 days, being collected $1 \mathrm{~mL}$ from each sample every 5 days. Then, centrifugation was performed and $145 \mu \mathrm{L}$ was removed from each sample and packed in a $2 \mathrm{~mL}$ microtube. Next, $570 \mu \mathrm{L}$ of distilled water was added and $285 \mu \mathrm{L}$ from ammonium mobidate-vanadato reagent was added. Ten minutes after the reagent was added, spectrophonomester absorbance (UV model - SP 2000 Biospectro) was performed under optical density of $420 \mathrm{~nm}$ and applied in the formula $\left(y=0.3041^{*} X^{2}+0.2566^{*} X+0.0213\right)^{*} 1000$. The experimental design was entirely randomized with four replications in a plot scheme subdivided in time. The data obtained were submitted to variance analysis and the means compared by the Tukey test $(p>0.05)$. The results showed a range of $10-141 \mu \mathrm{g} \cdot \mathrm{mL}^{-1} \mathrm{P}$, characterizing with high solubilization and conferring these strains as phosphate solubilizers. The most efficient strains were F04 and F05.
\end{abstract}

KEYWORDS: Filamentous fungi, fosfatase, calcium phosphate

\section{INTRODUÇÃO}

Por suas condições naturais, o solo abriga uma diversidade de micro-organismos, os quais diferem entre si por meio de seus caracteres funcionais como a capacidade de prover crescimento vegetal por meio de produção de hormônios e reguladores de crescimento vegetais (Oliveira et al., 2012), controle biológico de doenças e pragas (Silva et al., 2015; Simi et al., 2018) e 
solubilização de fosfatos (Vera et al., 2002). Assim, com o intermédio desses caracteres, fungos são capazes de promover o crescimento vegetal.

Em vista às adversidades ambientais e as mudanças climáticas, trabalhos vêm sido desenvolvidos com a finalidade de se prospectar a existência de fungos com aplicabilidades agropecuárias. Desse modo, Silva et al. (2019) descrevem que ambientes extremos como solo altamente halófilos e com ausência de disponibilidade hídrica abrigam fungos filamentosos em associação com as plantas.

OPé um elemento limitante na agricultura, o que tem gerado uma grande discussão quanto a utilização de micro-organismos solubilizadores deste elemento. Assim, micro-organismos já tem sido descrito como solubilizadores de fosfato em estudos prévios (Silva et al., 2015; Silva et al., 2018). Este elemento, além de atuar diretamente na nutrição mineral das plantas cultivadas, participa dos processos metabólicos das mesmas, sendo, portanto, um elemento fundamental no desenvolvimento vegetal.

Diante do exposto, objetivou-se por meio desse trabalho, avaliar o potencial de solubilização de fosfato de seis cepas fúngicas isoladas de solo halófilo em processo de desertificação no Semiárido alagoano.

\section{MATERIAL E MÉTODOS}

Os ensaios foram realizados no Laboratório de Microbiologia Agrícola do Centro de Ciências Agrárias da Universidade Federal de Alagoas (CECA-UFAL) e no Laboratório de Solos do Instituto Federal de Educação de Alagoas Campus Murici. As cepas fúngicas rizosféricas utilizadas estão devidamente depositadas e conservadas no laboratório de Microbiologia Agrícola CECA-UFAL.

As cepas foram crescidas previamente em meio de cultura Batata Dextrose Agar (BDA) em placas de Petri por cinco dias. Posteriormente, um disco de micélio de aproximadamente $1 \mathrm{~cm}$ foi retirado da placa e inoculado em erlenmeyers contendo $100 \mathrm{~mL}$ de meio de cultura NBRIP (Nautiyal, 1999) e incubado por 15 dias em agitador orbital sob rotação de $120 \mathrm{rpm}$ à temperatura ambiente.

A cada cinco dias foi removido de cada erlenmeyers $1 \mathrm{~mL}$ do sobrenadante do meio de cultura, 0 qual foi acondicionado em microtubos e congelado $\left(\approx 6^{\circ} \mathrm{C}\right)$ para posteriores análises.
Então, $1000 \mu \mathrm{L}$ de cada amostra foi centrifugado a $10000 \mathrm{rpm}$ por cinco minutos. Em seguida, $145 \mu \mathrm{L}$ da amostra foi transferido para novos microtubos e acrescido $570 \mu \mathrm{L}$ de água destilada e $285 \mu \mathrm{L}$ do reagente molibidato-vanadato de amônio (5\% molibidato, 0,25 vanadato de amônio (v/v)). As amostras foram então reservadas por 10 minutos e procedida, em seguida, a leitura da absorbância sob densidade óptica a $420 \mathrm{~nm}$ em espectrofotômetro (modelo SP-2000, Biospectro) (Malavolta et al., 1989; Silva, 1999). A concentração de $P$ em $\mu \mathrm{g} \cdot \mathrm{mL}-1$ foi determinada por meio da equação $y=$ $\left(0,3041^{*} X^{2}+0,2566^{*} X+0,0213\right)^{*} 100$, onde interpreta-se os valores: baixa solubilização $\left(<50 \mu \mathrm{g} \cdot \mathrm{mL}^{-1}\right)$; média solubilização (50-100 $\left.\mu \mathrm{g} \cdot \mathrm{mL}^{-1}\right)$; alta solubilização (101$\left.500 \mu \mathrm{g} \cdot \mathrm{mL}^{-1}\right)$ e elevada solubilização (>501 $\left.\mu \mathrm{g} \cdot \mathrm{mL}^{-1}\right)$.

0 delineamento experimental foi em blocos inteiramente casualizados com quatro repetições em esquema de parcelas subdivididas no tempo, onde cada tratamento correspondeu a uma cepa fúngica. O tratamento controle correspondeu ao Erlenmeyer contendo somente o meio de cultivo sem inóculo. Os dados obtidos foram tabulados e submetidos à análise de variância por meio do software Sisvar (Ferreira, 2014) e os valores comparados pelo teste de Tukey ( $p$ $\leq 0,05)$.

\section{RESULTADOS E DISCUSSÃO}

Todas as cepas aqui estudadas apresentaram crescimento micelial no meio de cultivo. Por meio da análise de variância, foram detectadas diferenças significativas entre as cepas estudadas ( $p \leq 0,05$ ). Assim, genericamente falando, as cepas F04 e F05 foram as mais promissoras na solubilização de fosfatos inorgânicos, com resultados superiores aos demais. Porém, não foram detectadas relações entre o tempo de incubação e a solubilização de fosfatos, considerando assim que essa característica é eminente de cada uma das cepas, as quais apresentam comportamentos distintos.

Nesse aspecto, a cepa F04 apresentou as maiores concentrações de $\mathrm{P}$ com $121 \mu \mathrm{g} \cdot \mathrm{mL}^{-1}$ a partir do quinto dia de incubação, seguido pela cepa F05 com concentração de $100 \mu \mathrm{g} \cdot \mathrm{mL}^{-1}$. Porém, a atividade da fosfatase, responsável pela solubilização de $P$, apresenta decréscimo para F04 ao décimo dia de incubação (Tabela 1). Para a cepa F05, a partir do décimo dia ocorre estabilização da solubilização de fosfato. A cepa F01 apresenta pico de solibilização 
Tabela 1. Concentração de P em meio de cultura NBRIP, por cepas fúngicas isoladas de rizosfera de cactáceas do Semiárido alagoano durante 15 dias de incubação.

\begin{tabular}{cccc}
\hline \multirow{2}{*}{ Cepa } & \multicolumn{3}{c}{ Dias de incubação } \\
\cline { 2 - 4 } & 5 & 10 & 15 \\
\hline F01 & $54,64 \mathrm{a}^{*}$ & $58,56 \mathrm{ab}$ & $82,62 \mathrm{ab}$ \\
F02 & $21,59 \mathrm{a}$ & $11,09 \mathrm{a}$ & $25,84 \mathrm{ab}$ \\
F03 & $36,98 \mathrm{a}$ & $34,17 \mathrm{ab}$ & $49,3 \mathrm{ab}$ \\
F04 & $121,79 \mathrm{a}$ & $134,4 \mathrm{~b}$ & $107,69 \mathrm{ab}$ \\
F05 & $99,98 \mathrm{a}$ & $141,51 \mathrm{~b}$ & $141,83 \mathrm{~b}$ \\
F06 & $8,39 \mathrm{a}$ & $10,72 \mathrm{a}$ & $11,12 \mathrm{a}$ \\
\hline
\end{tabular}

${ }^{*}$ Médias seguidas de mesma letra nas colunas não diferem estatisticamente entre si (Tukey $p \leq 0,05$ ).

ao $15^{\circ}$ dia de incubação, podendo considerar que a atividade fosfatase dessa cepa seja constante e que necessite de mais tempo para obter maiores concentrações de solubilidade de P. Os caracteres apresentados em função dos valores de P solubilizados conferem as cepas F04 e F05 com alta capacidade de solubilização de fosfato.

Assim, todos os fungos estudados apresentaram capacidade de solubilização de fosfato em meio de cultura NBRIP, com variação de 10 a $141 \mu \mathrm{g} \cdot \mathrm{mL}^{-1}(\approx)$. Resultados semelhantes já tem sido descritos na literatura em estudos anteriores, como demonstrado por Oliveira et al. (2012) ao estudar a solubilização de fosfato por diferentes cepas de Trichoderma sp., onde os autores afirmam que tais fungos apresentaram crescimento micelial e variáveis valores de concentração de $\mathrm{P}$ utilizando o mesmo meio de cultivo.

Quanto a quantidade de $\mathrm{P}$ solubilizado em função do tempo de incubação, Montaldo (2016) afirma que essa característica é uma das mais importantes quanto ao screening de micro-organismos para a produção de inoculantes, uma vez que esse aspecto confere constância na solubilização desse elemento. Ademais, a capacidade de solubilizar fosfatos está relacionada à produção de ácidos orgânicos, como relatado em alguns estudos (Zaidi et al., 2009).

Fungos rizosféricos associados à cactáceas são capazes de solubilizar fosfatos inorgânicos. Sua capacidade de solubilização é variável de acordo com cada cepa e também sofrem interferência estrita do tempo de incubação.

\section{AGRADECIMENTOS}

Coordenação de aperfeiçoamento de pessoal de nível superior (CAPES).

\section{REFERÊNCIAS BIBLIOGRÁFICAS}

Ferreira, D. F. Sisvar: a Guide for its Bootstrap procedures in multiple comparisons. Ciência e Agrotecnologia, 2014, 38, 2, 109-112.

MALAVOLTA, E., VITTI, G.C., OLIVEIRA, S.A. Avaliação do estado nutricional das plantas: princípios e aplicações. Piracicaba: Potafós, 1997. 319p.

Montaldo, Y. C. Bioprospecção e isolamento de bactérias associadas à cana-de-açúcar (Saccharum officinarum L.) com características para a promoção de crescimento vegetal. 2016. $101 \mathrm{f}$. Tese (Doutorado em Rede Nordeste de Biotecnologia) Maceió, Alagoas, 2016.

Nautiyal, C. S. An efficient microbiological growth medium for screening phosphate solubilizing microorganisms. FEMS Microbiological Letters, 1999, $170,1,265-270$.

Oliveira, A. G.; Xhagas Junior, A. F.; Santos, G. R.; Miller, L. O.; Chagas, L. F. B. Potencial de solubilização de fosfato e produção de AIA por Trichoderma spp.. Revista Verde de Agroecologia e Desenvolvimento Sustentável, 2012, 7, 3, 149-155.

Silva, C. S.; Tenório, F.A.; Silva, J. M.; Guedes-Celestino, E. L. F.; Araújo, R. G. V.; Lima, J. R. B.; Montaldo, Y. C.; Santos, T. M. C. Solubilização de fosfatos inorgânicos por bactérias endofíticas isoladas de maracujá amarelo (Passiflora edulis Sims f. flavicarpa). Revista Craibeiras de Agroecologia, 2018, 1.

Silva, F. C. Manual de análises químicas de solos, plantas e fertilizantes. Brasília: Embrapa Solos, 1999, 370p. 
Silva, J. M.; Nascimento, S. P. G.; Massahud, R. T. R.; Santos, T. M. C.; Lima, G. S. A. Atributos químicos e biológicos do solo: Um estudo no Semiárido alagoano. In: Ensaios interdisciplinares em ciências agrárias. Gomes, I. A.; Medeiros, M. B.; Batista, M. C.; Gonzaga, K. S.; Felix, R. J. S.; Silva Junior, J. M.; Santos, J. P. O. Edição n 1. 2019, vol. 1, pp. 42-50.

Silva, J. M.; Santos, T. M. C.; Albuquerque, L. S.; Montaaldo, y. v.; Oliveira, J. U. L.; Silva, S. G. M.; Nascimento, M. S.; Teixeira, R. R. O. Potential of the endophytic bacteria (Herbaspirillum spp. and Bacillus spp.) to promote sugarcane growth. Australian Journal of Crop Science, 2015, 9, 8, 754-760.

Simi, L. D.; Leite, L. G.; Trevisan, O.; Costa, J. N. M.; Oliveira, L. E.; Schmidt, F. S.; Bueno, R. N. S.; Batista
Filho, A. Mortality of Conotrachelus humeropictus in response to combined application of the nematode Steinernema brazilense and the fungus Beauveria bassiana. Arquivos do Instituto Biológico, 2018. 85, 1-9.

Vera, D. F.; Pérez, H.; Valencia, H. Aislamiento de hongos solubilizadores de fosfatos de la rizósfera de Arazá (Eugenia stipitata, Myrtaceae). Acta Biologica Colombiana, 2002, 7, 1, 33-40.

Zaidi, A.; Khan, M. S.; Ahemad, M.; Oves, M.; Wani, P. A. Recent advances in plant growth promotion by phosphate-solubilizing microbes. In: Khan, M.; Zaidi, A.; Musarrat, J. (eds) Microbial Strategies for Crop Improvement. Springer, Berlin, Heidelberg, 2009, pp. 23. 